\title{
Studi Eksplorasi Potensi Pariwisata Kreatif Kawasan Hutan Mangrove Desa Sedari, Kecamatan Cibuaya, Kabupaten Karawang, Jawa Barat
}

\author{
Alexander Fiandre Readi 1), Jessica Christina ${ }^{2)}$, Myrza Rahmanita ${ }^{3)}$, Fetty Asmaniati ${ }^{4)}$ \\ Program Sarjana Pariwisata, Sekolah Tinggi Pariwisata Trisakti 1) 2) \\ Program Doktoral Pariwisata, Sekolah Tinggi Pariwisata Trisakti ${ }^{3)}$ \\ Program Magister Pariwisata, Sekolah Tinggi Pariwisata Trisakti ${ }^{4}$ \\ Jl. IKPN No. 1, Bintaro, Jakarta Selatan \\ E-mail:myrzarahmanita@stptrisakti.ac.id ${ }^{1)}$
}

\begin{abstract}
Abstrak
Pariwisata kreatif merupakan bentuk pariwisata alternatif yang prospektif untuk dikembangkan di Desa Sedari. Penelitian yang ada menunjukkan bahwa daya tarik utama kawasan hutan mangrove selama ini semata pemandangan yang cenderung tidak melibatkan partisipasi dan pengalaman wisatawan dalam kegiatan pariwisata. Hal ini mengindikasikan potensi yang ada belum sepenuhnya termanfaatkan optimal. Terlebih kegiatan pariwisata ditunda dan dihentikan sementara dengan adanya Pemberlakuan Pembatasan Kegiatan Masyarakat (PPKM) untuk mencegah meluasnya penyebaran pandemi COVID19. Tujuan penelitian ini mengeksplorasi potensi pariwisata kreatif kawasan hutan mangrove di Desa Sedari, Kecamatan Cibuaya, Kabupaten Karawang, Provinsi Jawa Barat, Indonesia. Penelitian ini menggunakan metode deskriptif dengan pendekatan eksploratif. Data primer dan sekunder diperoleh melalui wawancara serta studi pustaka. Penelitian ini menemukan bahwa (1) Hutan mangrove Desa Sedari memiliki potensi untuk pengembangan pariwisata kreatif; (2) Pengembangan ke arah pariwisata kreatif baru dimulai pada tahun 2021 namun belum terlaksana optimal dimana belum ada pengelolaan, pengelola maupun program yang terencana baik. (3) Bentuk pariwisata kreatif yang dapat dikembangkan di kawasan hutan mangrove, diantaranya birdwatching, pengolahan produk berbasis mangrove, maupun kegiatan wisata yang melibatkan partisipasi aktif wisatawan, juga kerjasama wisatawan dengan masyarakat lokal dan pengelola kawasan hutan mangrove. Penelitian ini merekomendasikan dilakukannya renovasi dan revitalisasi sejumlah infrastruktur fisik kawasan hutan mangrove untuk pengembangan kegiatan pariwisata kreatif, peningkatan kompetensi dan kualifikasi sumber daya manusia pariwisata serta penguatan kemitraan kerja diantara para pemangku kepentingan terkait.
\end{abstract}

Kata Kunci: pariwisata kreatif, partisipasi aktif, hutan mangrove, desa sedari, pandemi COVID-19

\section{Explorative Study of the Creative Tourism Potential of the Mangrove Forest Area Sedari Village, Cibuaya District, Karawang Regency, West Java}

\begin{abstract}
Creative tourism is an alternative tourism that is prospective to be developed in Sedari Village. Existing research shows that the main tourist attraction of mangrove forest area in Sedari Village so far is mere the scenery which tends not to involve the participation and experience of tourists within the tourism activities. This indicates that the existing potential has not yet fully utilized. Moreover, tourism activities were temporarily postponed and stopped during the Public Activity Restrictions (PPKM) that carried out to prevent the spread of the COVID-19 pandemic. The purpose of this study was to explore the creative tourism potential of mangrove forest area in Sedari Village, Cibuaya District, Karawang Regency, West Java Province, Indonesia. This study utilised descriptive research method with exploratory approach. Primary and secondary data were obtained through interviews and literature study. This study found that (1) The mangrove forest of Sedari Village has the potential for the development of creative tourism; (2) Development towards creative tourism has not yet optimally implemented. It was just started in 2021 that there are no well-planned programs, managers nor management. At present; (3) Types of creative tourism can be developed in Sedari mangrove forest areas, including birdwatching, processing mangrove based tourism products; tourism activities involving tourist active participation, as well as tourist cooperation with local communities and mangrove forest area managers. This study recommends for the renovation and revitalization of a number of physical infrastructures for the development of
\end{abstract}


creative tourism activities; the enhancement of tourism human resources qualifications and competencies; as well as strengthening the working partnership amongst relevant stakeholders.

Keywords: creative tourism, active participation, mangrove forest, sedari village, pandemic COVID-19

\section{PENDAHULUAN}

Sektor pariwisata Indonesia merupakan salah satu penyumbang devisa negara terbesar dan berpotensi sebagai salah satu penopang utama perekonomian di masa mendatang, saat tidak memungkinkan kagi untuk mengandalkan minyak dan gas yang berpotensi habis dan tak tergantikan (Kemenparekraf, 2020). Merujuk hal tersebut, semua potensi kepariwisataan perlu dikembangkan termasuk hingga level desa, dimana desa wisata pada saat ini menjadi tren pariwisata dunia (Kemenparekraf, 2021).

Desa Sedari yang terletak di pesisir pantai utara pulau Jawa merupakan salah satu desa di Kecamatan Cibuaya, Kabupaten Karawang, Jawa Barat yang memiliki potensi kepariwisataan. Salah satu potensi pariwisata yang dimiliki Desa Sedari adalah kawasan hutan mangrove. Luas hutan mangrove di Desa Sedari (sekitar 49,20 ha dengan daya dukung fisik 32.800 jiwa/hari, daya dukung riil 25.047 jiwa serta daya dukung ekologi 26,65 ha (Hidayat, Riyantini, \& Pamungkas, 2020). Kawasan ini berpotensi untuk menjadi destinasi ekowisata yang mendukung pelestarian lingkungan dengan mangrove. (Friess, 2017)

Potensi hutan mangrove Desa Sedari berpotensi dikembangkan sebagai pariwisata kreatif (creative tourism) yaitu pariwisata yang berfokus pada pengembangan pengalaman kreatif skala kecil dan kegiatan belajar yang disediakan terutama oleh wirausahawan kreatif sebagai pelengkap produksi kreatif lainnya (Richards, 2014). Di Desa Sedari, sebagian masyarakat sudah melakukan kegiatan pariwisata kreatif, terutama dalam bentuk kriya, yaitu membuat hiasan dari akar mangrove dan dahan cemara di pinggir pantai (Awaludin, 2017).

Kajian hutan mangrove menunjukkan hanya tersedia jalan setapak untuk mengelilingi hutan mangrove, tidak optimal dan tidak terawat. Kegiatan wisata masih terbatas untuk melihat-lihat dan swafoto, serta belum banyak produk pemanfaatan tanaman bakau (Marsita, 2021). Di sisi lain, belum dioptimalkannya pemanfaatan potensi hutan mangrove Desa Sedari untuk pariwisata, ditunjukkan banyak fasilitas kegiatan wisata di kawasan hutan mangrove Desa Sedari yang kurang terawat dan rusak. Atraksi yang memiliki nilai tertinggi dari wisata kawasan hutan mangrove adalah pemandangan (Krisdyawati, \& Yusuf, 2021). Hal ini mengindikasikan bahwa potensi yang ada belum dimanfaatkan secara kreatif.

Penelitian ini ditujukan untuk mengeksplorasi potensi pariwisata kreatif kawasan hutan mangrove Desa Sedari, Kecamatan Cibuaya, Kabupaten Karawang, Jawa Barat, Indonesia.

\section{KAJIAN PUSTAKA}

\section{Pariwisata Kreatif}

Hermantoro (2011) menjelaskan bahwa pariwisata kreatif merupakan bentuk dari konsep pariwisata yang bertanggung jawab terhadap keberadaan komunitas lokal. Pariwisata kreatif dipahami sebagai pariwisata yang bertujuan untuk pengembangan diri, tidak bersifat masal, mengakomodasikan keberadaan usaha menengah dan kecil, memberikan ruang interaksi pada komunitas dan memberikan penghargaan pada lingkungan. Wisatawan atau pengunjung datang ke suatu desa dapat mempelajari tentang arsitektur bangunan dan kawasan, dan dapat menikmatinya dari suasana desa yang unik dari melihat atraksi seni budaya lokal. Richards (2014) menyatakan bahwa pariwisata kreatif adalah aktivitas kreatif berbasis pengetahuan yang menghubungkan produsen, konsumen, dan tempat wisata dengan memanfaatkan teknologi, bakat atau keterampilan untuk menghasilkan produk budaya takbenda yang bermakna, konten kreatif dan pengalaman. Marques (2019) memaparkan bahwa pariwisata kreatif merupakan pariwisata yang menawarkan wisatawan pengalaman berdasarkan kegiatan wisata yang melibatkan wisatawan itu sendiri. Pariwisata kreatif adalah kegiatan yang memberikan kesempatan bagi wisatawan untuk berpartisipasi dalam kegiatan yang terdapat di objek wisata, dengan tujuan untuk mengembangkan potensi kreatif yang dimiliki oleh si wisatawan, sesuai dengan destinasi pariwisata yang dituju olehnya.

Pembentuk pariwisata kreatif adalah pengalaman dan aktivitas wisatawan, sehingga kegiatan yang dilakukan oleh wisatawan dan output dari kegiatan tersebut berupa pengalaman berkesan yang dapat dirasakan 
dalam jangka waktu yang lama. Hal ini diutarakan oleh Richards dan Raymond (2000).

Pariwisata kreatif bersifat tidak berwujud sebagai bentuk daya tarik wisata budaya. Daya tarik wisata kreatif antara lain adalah seni dan arsitektur, warisan sejarah dan budaya, warisan kuliner, sastra, musik, industri kreatif dan kehidupan budaya dengan gaya hidup, sistem nilai, kepercayaan dan tradisinya, alam, kesenian, fesyen, kuliner, kesehatan, bahasa, dan olahraga (Richards \& Raymond, 2000; Richards, 2020). Pengembangan pariwisata kreatif dapat mengangkat budaya lokal yang dimiliki sehingga sejalan dengan prinsip pariwisata berkelanjutan (Kristiana et.al., 2020). Inti kreatif dari pariwisata kreatif pada dasarnya adalah proses pembelajaran yang menjadi fokus lokakarya interaktif dan pengalaman kreatif. Jenis kegiatan ini adalah inspirasi asli untuk konsep pariwisata kreatif dan gagasan untuk melibatkan pengunjung dalam kreativitas melalui pembelajaran tentang budaya, keterampilan, dan gagasan lokal (Duxbury \& Richards, 2019). Namun pariwisata kreatif lebih dari sekadar pembelajaran, pariwisata kreatif juga adalah tentang terlibat dengan tujuan wisata, tentang pengembangan keterampilan konsumsi, serta pengembangan narasi, makna, dan bahkan identitas baru di destinasi wisata (Richards, 2011).

Untuk potensi kreatif, pariwisata tergantung pada elemen tidak berwujud seperti gambar atau suasana tempat. Selain itu narasi dalam pariwisata sangat penting untuk menciptakan 'cerita' tentang orang dan tempat yang membuat tujuan tertentu lebih menarik sehingga wisatawan akan lebih mengingat pengalamannya (Richards, 2009; Nurbaeti et. al, 2021).

Partisipasi aktif adalah tentang proses di mana pelanggan berinteraksi dengan perusahaan atau masyarakat setempat dan menghasilkan pengalaman mereka sendiri (Prahalad \& Ramaswamy, 2004).

Pengalaman khusus untuk pariwisata kreatif menjiwai ruang publik dan pribadi, meremajakan struktur dan pemandangan jalan, meningkatkan kelangsungan bisnis lokal dan keamanan publik, dan menyatukan beragam orang untuk merayakan, menginspirasi, dan terinspirasi (Markusen \& Nicodemus, 2010). Wisatawan atau pengunjung yang datang ke suatu kampung bisa belajar dan menikmati suasana kampung yang unik dan spesifik serta bisa melihat atraksi seni budaya lokal (Resmawa \& Masuroh, 2019).
Kreasi bersama, mencakup penciptaan pengalaman bersama oleh konsumen dan produsen. Pengalaman kreatif lebih berfokus pada konteks konsumen dan disesuaikan dengan lingkungannya, dengan itu pengalaman wisatawan semakin meningkat (Binkhorst \& Dekker, 2009).

\section{Manfaat Pariwisata Kreatif}

Pariwisata kreatif secara langsung berimplikasi pada ekonomi melalui penerimaan devisa untuk negara, terbukanya kesempatan kerja, peningkatan pembangunan dan pendapatan pemerintah, peluang usaha, juga kewirausahaan, yang berimplikasi pada peningkatan kesejahteraan masyarakat (Cohen, 1984; Arismayanti, 2015).

Bagi wisatawan yang datang, pariwisata kreatif dapat menjadi sebuah pengalaman baru yang unik, memberi kesan pengalaman yang lebih tahan lama dan manfaat yang lebih luas (Richards dan Wilson, 2007). Mereka juga dapat lebih menghargai sekitarnya secara aktif melalui proses reflektif, kognitif dan psikologis afektif (Moscardo, 1996).

Pariwisata kreatif memberi wisatawan wawasan yang lebih dalam tentang tujuan wisata budaya, serta dengan tingkat pengembangan keterampilan tertentu (Richards dan Wilson, 2006, 2007; Smith, 2009). Dengan kegiatan yang ada, wisatawan juga dapat menghabiskan waktu yang menyenangkan bersama keluarga, teman, atau wisatawan lain, serta bersenang-senang melalui pengalaman yang disediakan.

\section{HASIL DAN PEMBAHASAN}

\section{Pariwisata Kreatif}

Kawasan hutan mangrove Desa Sedari memiliki potensi pariwisata kreatif yang besar. Narasumber kepala Desa Sedari Bisri Mustopa, menyebutkan bahwa masyarakat memiliki kesiapan dan sangat kooperatif dalam pengembangan pariwisata di Desa Sedari. Saat dilakukannya penelitian ini belum ada kegiatan pariwisata kreatif di kawasan hutan mangrove yang memadai karena Desa Sedari masih cukup baru dalam pengembangan pariwisata.

Pengembangan pariwisata Desa Sedari baru dimulai pada tahun 2018. Sedangkan pengembangan wisata alam hutan mangrove sendiri oleh masyarakat Desa Sedari baru dimulai di tahun 2019. Kerjasama yang dilakukan oleh pemerintah Desa Sedari adalah dengan pihak pemangku kepentingan lokal, 
Perhutani dan Dinas Pariwisata dan Kebudayaan (Disparbud) baru dilaksanakan pada tahun 2021.

Kegiatan wisata di kawasan hutan mangrove yang dilakukan para wisatawan selama ini terbatas hanya melihat-lihat pemandangan dan swafoto. Foto dan video pengalaman selama berwisata di kawasan hutan mangrove tersebut diunggah ke media sosial, seperti Facebook dan Instagram.

Menurut narasumber, keadaan wisata kawasan hutan mangrove saat ini sedikit memprihatinkan karena sejumlah fasilitas penunjang pariwisata yang ada, seperti jalan setapak dan lokasi untuk berfoto. sudah rusak karena sudah lama dan tua usianya serta tidak ada perawatan maupun perbaikan. Pada saat dilakukan penelitian ini, wisata di kawasan hutan mangrove Desa Sedari sedang ditutup untuk umum karena pembatasan sosial pandemi COVID-19 dan sedang dilakukan renovasi.

\section{Potensi Kreatif}

Potensi kreatif terbentuk dari potensi kreatif masyarakat atau komunitas lokal dan destinasi wisata.

Potensi kreatif masyarakat serta komunitas lokal khususnya terkait hutan mangrove Desa Sedari belumlah optimal, utamanya dalam pemanfaatan dan pengolahan hasil hutan mangrove. Potensi pemanfaatan dan pengolahan hasil hutan mangrove oleh masyarakat lokal diantaranya dapat untuk menghasilkan produk turunan tanaman mangrove seperti makanan, minuman serta suvenir. Narasumber Kepala Bidang Pemasaran Disparbud, Hendrayana menyampaikan bahwa masyarakat Desa Sedari pernah mendapat pendidikani dan pelatihan dalam pemanfaatan hutan mangrove dan pengolahan hasilnya baik buah maupun pohonnya. Hal ini menjadi indikasi baik pengembangan potensi pariwisata kreatif. Seperti disampaikan oleh Hidayat, Rahmanita \& Hermantoro (2017), kegiatan pengembangan diri dan masyarakat dalam bentuk pendidikan dan pelatihan merupakan wujud upaya pemberdayaan masyarakat melalui pariwisata. Kegiatan pelatihan pengolahan mangrove pernah dilakukan bagi ibu rumah tangga di Desa Sedari, diantaranya menjadi sirop, kue, wajik, dan lainnya. Namun kala itu produk dari hasil kegiatan pelatihan tersebut tidak ditujukan untuk dijual. Temuan saat ini menunjukkan para ibu rumah tangga Desa Sedari sangat antusias untuk kembali http://ejournal.bsi.ac.id/ejurnal/index.php/khasanah melakukan pengolahan dan produksi tanaman mangrove. Saat penelitian dilakukan, kegiatan pengolahan mangrove untuk wisatawan belum ada karena belum adanya rencana pengelolaan pohon dan buah mangrove, sehingga belum dapat dipastikan rencana kegiatan pengolahan mangrove bagi wisatawan.

Potensi kreatif pengolahan hasil hutan dapat dikembangkan menjadi ekonomi kreatif serta sarana tercapainya indikator lain yaitu partisipasi aktif, pengalaman khusus dan kreasi bersama. Sebagai ekonomi kreatif maka kegiatan pengolahan hasil hutan mangrove tersebut akan berkelanjutan karena masyarakat lokal bisa memperoleh pendapatan dan manfaat dari kegiatan tersebut. Pengolahan dan pemasaran produk mangrove layak jual dapat dilakukan, baik di kawasan hutan mangrove maupun luar Desa Sedari.

Di sisi lain, proses penanaman dan pengolahan hasil hutan mangrove ini bisa menjadi kegiatan yang melibatkan partisipasi aktif wisatawan serta menjadi pengalaman khusus yang bersifat personal.

\section{Potensi Kreatif Kawasan Hutan Mangrove.}

Hutan mangrove Desa Sedari merupakan habitat bagi sejumlah spesies burung. Menurut Hendrayana, di hutan mangrove Desa Sedari pernah ditemukan spesies burung dari Bali. Menurut Hidayat, Riyantini, \& Pamungkas (2020), di hutan mangrove Desa Sedari ditemukan banyak burung kuntul kecil dan bangau. Burung bangau ditemukan dekat kawasan hutan mangrove, di area tambak ikan milik masyarakat. Keberadaan spesies burung ini merupakan potensi wisata berupa pengamatan burung (bird-watching).

Aktifitas pengamatan burung (birdwatching) untuk wisata memiliki peluang besar untuk berkembang karena merupakan kegiatan yang relatif baru untuk sebagian besar wisatawan. Birdwatching mulai muncul pada awal abad ke-20 (Kronenberg, 2014) dan memiliki potensi wisata kreatif sesuai pendapat Vaske dalam Janeczko (2021) yang membedakan jenis wisatawan birdwatching menjadi wisatawan yang sangat terlibat, wisatawan kreatif, wisatawan generalis dan wisatawan biasa.

Potensi lainnya adalah kawasan hutan mangrove yang memiliki suasana sejuk karena pohon mangrove rindang dan teduh, walaupun berada di pantai utara Karawang yang udaranya sangat panas. Dengan potensi ini dapat dikembangkan berbagai kegiatan wisata, 
baik alam, minat khusus maupun ekowisata seperti hiking; berperahu seperti boating, canoeing ataupun kayaking; dapat juga melakukan penanaman dan konservasi mangrove, edutour hutan mangrove. Ekowisata sekaligus menjadi sarana melakukan konservasi hutan mangrove. (Freiss, 2017; Spalding \& Parrett, 2019)

\section{Potensi Partisipasi Aktif}

Potensi pariwisata kreatif meliputi partisipasi aktif wisatawan dalam kegiatan pariwisata. Selama ini, keterlibatan para wisatawan dalam berwisata di Kawasan wisata hutan mangrove Desa Sedari terbatas mengunggah foto perjalanan wisata yang mereka lakukan. Partisipasi aktif wisatawan berupa keterlibatan dalam kegiatan wisata di kawasan hutan mangrove hampir tidak ada. Kalaupun ada, kerap disertai peran organisasi luar dan bukan penawaran dari pengelola kawasan hutan mangrove ataupun dari kelembagaan Desa Sedari.

Menurut penjelasan Mustopa, partisipasi aktif wisatawan berupa penanaman tanaman mangrove di Desa Sedari pernah dilakukan berdasarkan permintaan dari sebuah organisasi di Bandung. Dalam kegiatan ini pihak desa menyediakan benih mangrove untuk ditanam. Namun kegiatan tersebut hanya berlangsung satu kali.

Potensi yang dimiliki Desa Sedari untuk mendukung partisipasi aktif wisatawan dalam kegiatan pariwisata kreatif di kawasan hutan mangrove adalah kesiapan sumber daya manusia di Desa Sedari. Lembaga Masyarakat Desa Hutan (LMDH). Desa Sedari memiliki sumber daya manusia yang memiliki pengalaman dalam penanaman mangrove. Mereka berpengalaman tentang bagaimana cara menanam mangrove, memperhitungkan kedalaman air yang tepat untuk setiap jenisnya. Mereka tidak mendapatkan pendidikan secara formal melainkan belajar melalui pengalaman.

Dengan adanya sumber daya manusia tersebut, pengelola bisa menawarkan partisipasi aktif untuk pengalaman wisatawan (tourist experience) dalam kegiatan pariwisata kreatif kawasan hutan mangrove Desa Sedari. Pengalaman wisatawan bisa menjadi motivasi wisatawan melakukan kunjungan ulang ke destinasi jika pengalaman tersebut menjadi pengalaman wisatawan yang tidak terlupakan (Dagustani, Kartini, Oesman, \& Kaltum, 2018).

Akan tetapi kegiatan kreatif yang memungkinkan wisatawan individual untuk membuat atau mempelajari sesuatu yang khas serta berinteraksi dengan masyarakat lokal dari tempat wisata tersebut belum terprogram. Karena bagimanapun keterlibatan masyarakat memegang peranan penting dalam industri pariwisata yang dikembangkan dengan ciri khas daya tarik wisatanya (Rahmanita, Asmaniati \& Dewi, 2020). Partisipasi aktif masyarakat dalam kegiatan pariwisata mempengaruhi tingkat konsumsi pengunjung yang tentunya akan meningkat karena dengan intensnya masyarakat yang terlibat langsung dalam kegiatan pembangunan maka konsumsi wisatawan juga akan meningkat (Ashartono, Rahmanita \& Lemmy, 2018)

\section{Potensi Pengalaman Khusus}

Pengalaman khusus yang ditawarkan di kawasan hutan mangrove Desa Sedari yang dinikmati sebagian besar wisatawan saat ini masih tentang keaslian dan keasrian hutan mangrove. Wisatawan yang berkunjung sekedar berjalan-jalan, melihat dan menikmati suasana hutan mangrove yang rindang.

Bagi wisatawan yang berkunjung dari daerah kota mendapatkan pengalaman khusus yang berbeda dengan apa yang dihadapinya sehari-hari. Ada pula wisatawan yang berkunjung ke Desa Sedari untuk nilai sejarahnya, yaitu melihat prasasti Peringatan Hari Pangan Sedunia tahun 1992, yang ditandatangani oleh Presiden $\mathrm{Rl}$ kedua, Soeharto.

Potensi lain yang bisa dikembangkan sebagai parwiisata kreatif adalah atraksi seni budaya lokal, antara lain berupa acara yang dilaksanakan satu tahun sekali yaitu Nadran dan Baritan. Nadran dan Baritan merupakan kegiatan masyarakat Desa Sedari sebagai wujud rasa syukur atas semua hasil yang mereka peroleh selama ini.

Mustopa sebagai Kepala Desa Sedari ingin mengembangkan kegiatan syukuran ini sebagai warisan budaya lokal yang dapat dinikmati juga oleh wisatawan karena selama ini kegiatan Nadran dan Baritan ini belum dapat ditampilkan dan dilihat langsung oleh wisatawan karena keterbatasan lokasi.

Dalam rangka optimalisasi pemeliharaan dan pengembangan seni dan budaya, menurut Hendrayana, para seniman yang ada di Desa Sedari diwadahi dalam bentuk Forum Kesenian Daerah.

\section{Potensi Kreasi bersama}

Potensi ini merupakan potensi melakukan kegiatan kreasi bersama antara wisatawan dan penyelengaran atau pengelola 
wisata alam hutan mangrove. Namun kegiatan tersebut belum terlaksana di Kawasan hutan mangrove Desa Sedari karena belum adanya perencanaan.

\section{Pengembangan Pariwisata Kreatif}

Kendala pengembangan pariwisata kreatif kawasan hutan mangrove Desa Sedari diantaranya adalah infrastruktur. Infrastruktur wisata di hutan mangrove Desa Sedari belum memadai, belum terdapat jalan setapak yang layak dan nyaman untuk wisatawan berjalanjalan. Sebagian jalan masih berupa tanah dan hanya sebagian jalan setapak yang berupa jalan bersemen serta dilapisi bambu. Beberapa spot foto buatan yang telah dibangun sebelumnya juga mengalami kerusakan karena using dan lapuk sehingga tidak dapat digunakan lagi. Pada saat ini sedang diadakan renovasi untuk spot foto, loket tiket, serta gapura pintu masuk, juga perbaikan akses jalan menuju Desa Sedari. Hal-hal tersebut belum mencukupi untuk menarik minat wisatawan berkunjung ke hutan mangrove Desa Sedari

Lebih lanjut, pengembangan pariwisata di hutan mangrove Desa Sedari masih sangat baru. Penyelenggaraan dan pengelola nya juga baru berpindahtangan. Akan tetapi dengan adanya perjanjian kerjasama yang disetujui dalam Nota Kesepahaman antara Perusahaan Umum Kehitanan Negara Indonesia (Perum Perhutani) dan Lembaga Masyarakat Desa Sedari, serta adanya kesepakatan antara pemangku kepentingan dengan pemerintah Desa Sedari, dan juga antusiasme masyarakat lokal untuk partisipasi dalam pengolahan mangrove menjadi indikasi bahwa pariwisata kreatif hutan mangrove Desa Sedari sangat potensial dan siap untuk dikembangkan.

Peran pemerintah desa dan daerah sangat diperlukan dalam pengembangan pariwisata kreatif di hutan mangrove Desa Sedari. Pariwisata harus memiliki implikasi ekonomi pada pendapatan dan usaha masyaraka lokal. Pemerintah daerah dan pemangku kepentingan lainnya harus lebih memperhatikan tidak hanya aspek lingkungan dan sosial, tetapi juga ekonomi. (Rahmanita, Asmaniati \& Dewi, 2020).

Namun terjadinya pandemi COVID-19 membawa pengaruh dan berdampaik terhadap renovasi yang sedang dilakukan dan rencana pembangunan Desa Sedari. Pada saat penelitian ini dilakukan pada bulan Juli 2021, pemerintah Indonesia menyatakan kenaikan kasus tertinggi secara berturut-turut dan menyentuh angka kematian tertinggi selama pandemi COVID-19 di Indonesia (Sagita, 2021). Diikuti juga Pemberlakuan Pembatasan Kegiatan Masyarakat (PPKM) Mikro Darurat yang mulai berlaku pada 3 Juli hingga 20 Juli 2021 untuk wilayah Jawa dan Bali diberlakukan (Asmara, 2021) menyebabkan semua aktifitas kepariwisataan ditunda ataupun dihentikan sementara waktu.

\section{PENUTUP}

Penelitian ini menemukan bahwa (1) Hutan mangrove yang dimiliki Desa Sedari berpotensi untuk dilakukannya pengembangan pariwisata kreatif. (2) Belum dikembangkannya pariwisata kreatif di kawasan hutan mangrove di Desa Sedari dikarenakan pengelola dan pengelolaan yang baru berpindahtangan serta belum adanya program yang direncanakan secara baik; kegiatan pariwisata di kawasan hutan mangrove tersebut baru dimulai pada tahun 2021, dimana aktifitas wisatawan saat ini semata terbatas pada melihat-lihat dan berfoto; sejumlah infrastruktur yang ada untuk wisata hutan mangrove lapuk dan using serta memerlukan renovasi; diperberat dampak pandemi COVID-19 memaksa semua kegiatan ditunda (3) Pernah dilakukannya kegiatan yang mengarah pada pariwisata kreatif meski bukan inisiatif pengelola melainkan pihak eksternal, berupa yaitu penanaman pohon mangrove oleh wisatawan bisa sebagai motivasi dan awal pengembangan pariwisata kreatif di kawasan hutan mangrove Desa Sedari. (4) Sejumlah aktifitas pariwisata kreatif berpotensi dikembangkan di Desa Sedari antara lain birdwatching untuk pengamatan burung di kawasan hutan mangrove; serta pengolahan hasil produksi tanaman mangrove. Potensi pariwisata yang melibatkan partisipasi aktif wisatawan, juga kerjasama wisatawan dengan masyarakat lokal dan pengelola wisata hutan mangrove dapat berupa program penanaman pohon mangrove, pelatihan pengolahan hasil hutan mangrove untuk diproduksi sebagai makanan, minuman dan suvenir.

\section{DAFTAR PUSTAKA}

Ashartono, R., Rahmanita, M. \& Lemmy, D. M. (2018). The Effect of Destination Management and Community Participation to The Visitors Consumption at Tebing Breksi Sleman Yogyakarta. Tourism Research Journal, 2(1), 1-13 
Asmara, C.G. (2021, 1 Juli). Jokowi: PPKM Darurat Berlaku 3-20 Juli 2021 untuk Jawa-Bali! https://www.cnbcindonesia.com/news/ 20210701110812-4-257362/jokowippkm-darurat-berlaku-3-20-juli-2021untuk-jawa-bali (diakses 4 Juli 2021)

Arismayanti, N. K. (2015). Pariwisata Hijau Sebagai Alternatif Pengembangan Desa Wisata di Indonesia. Jurnal Analisis Pariwisata, 15 (1), 1-15.

Awaludin, L. (2017). Bukan Cuma Goyangan, Karawang Juga Punya Pantai Hits selengkapnya https://travel.detik.com/d omestic-destination/d-3756121/bukancuma-goyangan-karawang-jugapunya-pantai-hits (diakses 27 Agustus 2021)

Binkhorst, E., \& Den Dekker, T. (2009). Agenda for Co-Creation Tourism Experience Research. Journal of Hospitality Marketing \& Management, 18, 311327.

Dagustani, D., Kartini, D., Oesman, Y. M., \& Kaltum, U. (2018). Destination Image of Tourist: Effect of Travel Motivation and Memorable Tourism Experience. Etikonomi: Jurnal Ekonomi, 17(2), 307 $-318$.

doi: $\quad \mathrm{http} / \mathrm{dx}$.doi.org/10.15408/ etk.v17i2.7211.

Duxbury, N., \& Richards, G. (2019). Towards a research agenda for creative tourism: Developments, diversity, and dynamics. In A research agenda for creative tourism; 1 -14.

Friess, D. A. (2017). Ecotourism as a Tool for Mangrove Conservation. Sumatra Journal of Disaster, Geography and Geography Education, 1(1), 24-35

Hidayat, W. D. U., Riyantini, I. \& Pamungkas, W. (2020). Analysis of Suitability and Carrying Capacity of Mangrove Ecotourism in Sedari Village, Karawang District. E-Journal of Tourism, 7(1), 157-167

Hidayat, A., Rahmanita, M., \& Hermantoro, H. (2017). Community Empowerment in Plempoh Cultural Tourism Village.Tourism Research Journal, 1 (1), 98-116

Hermantoro, H. (2011). Creative-Based Tourism. Depok: Aditri.

Janeczko E., Łukowski A, Bielinis E, Woźnicka M., Janeczko K., \&Korcz N (2021). Not just a hobby, but a lifestyle": Characteristics, preferences and self- perception of individuals with different levels of involvement in birdwatching. PLOS ONE, 16(7), e0255359. https://doi.org/10.1371/journal.pone.02 55359

Kemenparekraf (2020). Laporan Kinerja Kementerian Pariwisata dan Ekonomi Kreatif/ Badan Pariwisata dan Ekonomi Kreatif. Jakarta: Kemenparekraf

Kemenparekraf (2021). Membangun ekosistem desa wisata bersama komunitas. https://kemenparekraf.go.id/ragampariwisata/Membangun-EkosistemDesa-Wisata-Bersama-Komunitas

Krisdyawati, N \& Yusuf, A.(2021). Pengaruh persepsi kualitas terhadap minat kunjungan ulang (survei pada pengunjung wisata mangrove sedari karawang. The Asia Pacific Journal of Management, 8(1), 11-20

Kristiana, Y., Pramono, R., Nathalia, T. C., \& Goeltom, V. A. H. (2020). Tourism and original local government revenue in Indonesia Tourism Provinces: The Java Island experience. Systematic Reviews in Pharmacy, 11(9), 745-750. https://doi.org/10.31838/srp.2020.9.10 5

Kronenberg J. (2014). Environmental Impacts of the Use of Ecosystem Services: Case Study of Birdwatching. Environmental Management, 54, 617630

Markusen, A., \& Nicodemus, A.G. (2019). Creative placemaking: Reflections on a 21st-century American arts policy initiative. Dalam Courage, C \& McKeown, A (Eds). Creative Placemaking: Research, Theory and Practice. Routledge

Marsita (2021). Analisis Potensi dan Strategi Pengembangan Wisata Alam Pantai Sedari Kabupaten Karawang. Tesis Program Magister Pariwisata STP Trisakti

Marques, L. (2019). The making of the literary city: Edinburgh, Barcelona and Óbidos. Dalam I. Jenkins, \& K. A. Lund (Eds.). Literary tourism: Theories, practice and case studies, (57-70). Wallingford: $\mathrm{CABI}$

Nurbaeti., Rahmanita, M., Ratnaningtyas, H.,\& Amrullah. (2021). Pengaruh Daya Tarik Wisata, Aksesbilitas, Harga Dan Fasilitas Terhadap Minat Berkunjung Wisatawan Di Objek Wisata Danau 
Cipondoh, Kota Tangerang. Jurnal Imu Sosial dan Humaniora, 10(2), 269-278

Prahalad, C., and Ramaswamy, V. (2004). Cocreation experiences: The next practice in value creation", Journal of Interactive Marketing, 18 (3): 5-14.

Rahmanita, M., Asmaniati, F., \& Dewi, T.R., (2020) Profiling Local Business Enterprises and Direct Effect of Tourism in Villages of Muntei, Madobag and Matotonan, South Siberut, Mentawai, Indonesia. Tourism Research Journal, 4(2), 199-213

Richards, G., \& Raymond, C. (2000). Creative tourism. ATLAS News, 23(8), 16-20.

Richards, G. (2011). Creativity and tourism. The state of the art. Annals of Tourism Research.

https://doi.org/10.1016/j.annals.2011.0 7.008

Richards, G. (2014). Creativity and Tourism in the City. Current Issues in Tourism, 17(2), 119-144

Richards, G. (2020). Designing creative places: The role of creative tourism. Annals of Tourism Research 85,102922

Richards, G., \& Wilson, J. (2006). Developing creativity in tourist experiences: A solution to the serial reproduction of culture? Tourism Management, 27(6), 1209-1223.

Richards, G., \& Wilson, J. (2007). The creative turn in regeneration: Creative spaces, spectacles and tourism in cities. Dalam M. Smith (Ed.). Tourism, culture and regeneration, (12-24). London: Routledge.

Sagita, N.S.K.. (2021, 30 Juli). Kematian COVID-19 Juli Tertinggi Selama Pandemi, Ini Saran Satgas. https://health.detik.com/beritadetikhealth/d-5662882/kematian-covid19-juli-tertinggi-selama-pandemi-inisaran-satgas. (diakses 5 Agustus 2021)

Spalding, M. \& Parrett, C.L. (2019). Global patterns in mangrove recreation and tourism. Marine Policy, 110, 103540: 18.

https://doi.org/10.1016/j.marpol.201 9.103540

UNESCO (2006). Towards sustainable strategies for creative tourism: creative cities network: discussion report of the planning meeting for 2008 Internationale conference on creative tourism, Santa Fe, New Mexico, October 25-27,2006.

(http://unesdoc.unesco.org/images/001 5/001598/159811e.pdf

Vidal, R.V.V. (2009). To be human is to be creative. Al \& SOCIETY Journal of Knowledge, Culture and Communication, 24(1). 